\title{
Using Multiple Case Studies to Analyse Open Source Software Business Sustainability in Sub-Saharan Africa
}

\author{
Sulayman K. Sowe ${ }^{1}$ and Maurice McNaughton ${ }^{2}$ \\ ${ }^{1}$ United Nations University Institute of Advanced Studies (UNU-IAS) \\ 1-1-1 Minato Mirai, Yokohama, 220-8502, Japan \\ sowelias.unu. edu \\ ${ }^{2}$ Mona School of Business \\ University of the West Indies, Mona \\ maurice.mcnaughton@uwimona.edu.jm
}

\begin{abstract}
Amidst the debate about what sort of technology is appropriate for achieving sustainable development, Free and Open Source Software (FOSS) offers some solutions to today's technology problems for many developing countries. However, there is a paucity of empirical evidence to help us understand the potentials FOSS technologies have for small businesses in Sub-Saharan Africa. This research utilizes nine case studies data from seven African countries to find out how entrepreneurs are leveraging FOSS to help them create sustainable business based on openness. The findings show increasing awareness of the business potential of FOSS, and a business model incorporating both FOSS and proprietary software is needed to run a sustainable IT business in these countries. However, the lack of skilled FOSS developer base, the absence of appropriate policies, and poor payment habits by clients are just some of the factors affecting businesses. Other problems encountered, possible solutions to those problems and lessons to be learnt from each case study are also discussed. The research offers entrepreneurs, ICT practitioners, and policy makers the platform to understand the Why and How FOSS technologies are impacting the traditional way of doing business in Sub-Saharan Africa.
\end{abstract}

\section{$1 \quad$ Introduction}

The plethora of Free and Open Source Software (FOSS) applications available throughout the internet in projects and forges are not only having huge socioeconomic impact in many sectors in many different parts of the world, but are continuously redefining the way businesses (small and big) operate. The past few years have witnessed growing research interest in FOSS and its adoption and utilization in the business sector [16, 22, 28]. However, research results (e.g. [29, 30]) posit that in most businesses, FOSS solutions will not operate in isolation but will exist side by side with their commercial counterparts. In fact, [33] has conceptualized the "AIM Postulate", 
which advocates an emerging business posture towards software co-existence by moving away from (Fear, Uncertainty and Doubt/Distrust) FUD to collaborative ecosystems. The AIM postulate is grounded in the empirical observation of an emerging trend where businesses are more inclined to determine: "Where in my business operation do I need FOSS?" "How best can I leverage FOSS projects and communities to support my business?" According to AIM, software co-existence is all about

i. Applying best practices (closed or open) to software process, products, and services.

ii. Integrating with existing knowledge, experience, IT infrastructure, and

iii. Maximizing business value and organizational learning opportunities.

However, in many companies top level management still expressed some concerns towards full-scale FOSS adoption or the integration of FOSS technologies as a key business strategy [14]. Some of the concerns are associated with the difficulty of finding the right staff and developing the competencies necessary to work with FOSS [19]. Software support [27,9], quality [34], security, and the ability to integrate FOSS with existing infrastructure are also major concerns for many FOSS entrepreneurs.

The trend in the adoption and utilization of FOSS has remained, to a large extent, a phenomenon for the developed economies. For example, a series of case studies conducted by [25] shows that many regional municipalities in Europe are using FOSS. The Gartner study [12] reported that $85 \%(\mathrm{~N}=274)$ of enterprises in Asia Pacific, Europe and North America are using FOSS. Furthermore, the study projected that, by 2012 , at least $80 \%$ of all commercial software solutions will include substantive FOSS components. These findings are consistent with similar studies carried out by Actuate [1, 2], using data obtained from surveys conducted with about 1,000 businesses in North America, UK, Germany and France. In general, the economic impact of FOSS for Europe and the rest of the developed world are well documented in the FLOSS Impact report [13]. Research evidence on the adoption and utilization of FOSS in business environments tends to concentrate on big businesses from North America, Europe [1, 2], China [2], and Australia [14]. Furthermore, FOSS business models adopted by Europe SMEs have extensively been discussed by [8].

\subsection{Research Contribution and Questions}

According to the FOSSDeva survey [10], many people (65.91\%) strongly agree that FOSS is the way forward for developing countries; $51.14 \%$ see FOSS as a means to stimulate indigenous software industries, create local jobs, and lower technology acquisition costs. Over $60 \%$ believe that governments FOSS policy can help the spread and adoption of FOSS. Furthermore, [39] conducted an empirical study to investigate the main facilitators and inhibitors of FOSS adoption in the Tunisian software business sector. In another study, [40] discussed the perceptions, attitudes, and barriers to FOSS adoption and diffusion patterns in Jamaican SMEs. While, [21] discussed how the Chinese software industry can leverage the FOSS movement for its own development. Although these studies focus on FOSS adoption and diffusion in 
SMEs in developing countries, there exist diminutive research literature on FOSS business activities that can help us understand how small- and medium-sized enterprises (SMEs) in Sub-Saharan African are leveraging FOSS to either start their business ventures or enhance their existing business practices. The contribution of this research to the FOSS body of knowledge aims to fill this gap in the literature by offering answers to the following research question:

\section{How are small businesses in Sub-Saharan Africa leveraging benefits inherent in FOSS to create sustainable businesses?}

By addressing this question the research hopes to offer insight into other questions which may arise, such as

(i) how are Africa SMEs leveraging FOSS to support their business practices?

(ii) what are the FOSS business benefits for SMEs?

(iii) what problems or difficulties do they encounter and what are the possible solutions to those problems?

(iv) what lessons can we learn about the unique way of doing FOSS business in this part of Africa?

An empirical analysis of case studies data obtained from nine ICT-based SMEs from Uganda, Ethiopia, South Africa, Kenya, Tanzania, Nigeria, and Mozambique is used to show how the SMEs in these countries are leveraging benefits inherent in FOSS to create sustainable businesses. Business benefits include low business start-up and technology acquisition costs $[21,39,40]$, free access to source code and software, low total cost of ownership (TCO), availability of community support, and ability to customize the software to meet local business needs. A case study research strategy or approach advanced by [37] is used to gather the information needed to profile the companies, analyse their revenue generation models, capture their motivation for engaging in FOSS business, and list down some lessons that can be learnt from the way the companies operate.

This kind of research is important in a number of ways: increase our understanding of the FOSS business landscape in Sub-Saharan Africa, provide business opportunities by helping African entrepreneurs understand how to leverage the benefits inherent in FOSS, find possible ways of integrating FOSS into the African research and development agenda, provide guidelines for regional FOSS cooperation projects, integrate FOSS education into existing engineering curricular, and increase FOSS awareness on the continent. It is also hoped that this kind of research may act as an eye-opener for ICT businesses already investing or planning to do business in this region of the world. Furthermore, the findings from these case studies may provide guidelines for policymakers in the region to implement a "new" kind of ICT governance framework based on openness.

The rest of the paper is organized as follows. Section two presents background and related work on the impact and socioeconomic status of FOSS in the global and African context. The research methodology, presented in section three, demonstrates the use of a case study approach to investigate FOSS business sustainability. This is 
followed by section four where we present our analysis and discussion of the case studies results, as well as the validity threats and future work. Concluding remarks are presented in section five.

\section{Background and Related Work}

A multitude of interrelated factors are contributing to the upward trend in global adoption and utilization of FOSS. Some of these factors include: global acceptance that FOSS can stand at par and, even in some instances, perform better than its commercial proprietary counterparts [5, 15]; continued improvement in the quality of FOSS [34]; an alternative Bazaar style of developing software [26, 31]. The Bazaar as opposed to the Cathedral style of developing FOSS [26] harnesses diverse talents of globally distributed teams of software developers who, for the most part, freely volunteer their time and efforts to develop and maintain the software. The development model promises faster and cost effective software development cycle. Compared to proprietary software, FOSS is also said to have lower total cost of ownership. Entrepreneurs have hybrid business models opportunities [24, 8], customers are free from vendor lock-ins, users have greater learning and knowledge sharing prospects [32], and regions or countries can support technology independence $[7,20,23]$ by adopting and encouraging the use of FOSS.

The economic impact of FOSS is highlighted by many studies. For example, the IDC study [11] predicts that FOSS will grow at a $22.4 \%$ rate to reach US $\$ 8.1$ billion by 2013. The growth rate is mainly due to increased enterprise adoption from major firms such as IBM $[30,5]$, or Hewlett Packard. The study also found out that hybrid business models are taking more permanence in modern software business. That is, many proprietary software businesses or vendors are also involved in the development, deployment, support and maintenance, and even consultancy of FOSS solutions. These findings are consistent with a study carried out with U.S. companies and government institutions' usage of FOSS [36]. The authors found out that, motivated by reduce IT costs, faster systems delivery, and making systems more secure, $87 \%$ of the companies $(\mathrm{N}=512)$ surveyed are using FOSS, and bigger companies with at least US\$50 million annual revenue are more likely to use FOSS than smaller companies. This trend is in sharp contrast with what is observed in Europe, where small firms are the lead adopters of FOSS [17].

Thus, it can be argued that FOSS is really in vogue; the technology is having a real impact and redefining the software industry. There is gradual shift in focus from protecting software knowledge to maximizing gain from FOSS development, use, and distribution. As the FOSS development paradigm grants "free" access to the source code, software companies are not obligated to pay software licenses fees. If a company has staff with the technical knowledge, they can download and compile the source code, customize the software to suit the company's customer's needs, or even localize the software to suit a particular business market. However, if a company is not endowed with such technical savvies, it can leverage assistance available 24/7 in 
forums and mailing list or contract a vendor or a developer to carry out the modifications needed by the customer. Notwithstanding the availability of these community support options, it is more likely that the typical small business will be constrained by limited ICT literacy, and the lack of the business analytic skills, and absorptive capacity to effectively identify and deploy appropriate FOSS solutions to support their business. Hence intermediaries will play a crucial role in the adoption of complex ICT applications by SMEs, and strategically placed community intermediaries within local and regional and national business ecosystems will be essential to the effective adoption and diffusion of FOSS by SMEs [43] This provides new business models for ICT services SMEs in developing countries, where FOSS becomes both a compelling alternative to propriety software and an option to help them support a sustainable business. Another compelling reason, argued [40] is that the FOSS domain offers an increasingly mature portfolio of business applications that represents viable alternative solutions to meet customers' expectations.

Furthermore, FOSS can, arguably, bring about new business opportunities for small businesses in developing countries [7, 27, 28, 35]. For established SMEs, FOSS enables them to move from product-based to service-based (software hosting, support, consulting, training, integration, or customization) activities [39]. Generally, FOSS is increasingly being recognized by many governments, regional municipalities, and businesses as the means by which developing countries can expand their use of ICTs without the need for huge capital expenditure.

\section{Research Methodology}

The methodology employed in this research aims to investigate FOSS business sustainability in the African context. The methodology employs case studies to find out how and why FOSS is being used by ICT-based SMEs to support and sustain their business ventures. The reason for choosing case studies as research instruments is grounded on Yin's [37] argument that a case study design should be considered when "the focus of the study is to answer how and why questions" and when the researcher wants to "cover contextual conditions" which are believed to be relevant to the phenomenon under study. Thus, a case study approach is considered appropriate technique for this research since it can add value [4] and contribute to the body of knowledge by helping researchers and practitioners in the domain to better understand FOSS business sustainability in Sub-Saharan Africa. The methodology employed in this research is schematically shown in figure 1, with the key steps marked in circles and are numbered from 1-7. 


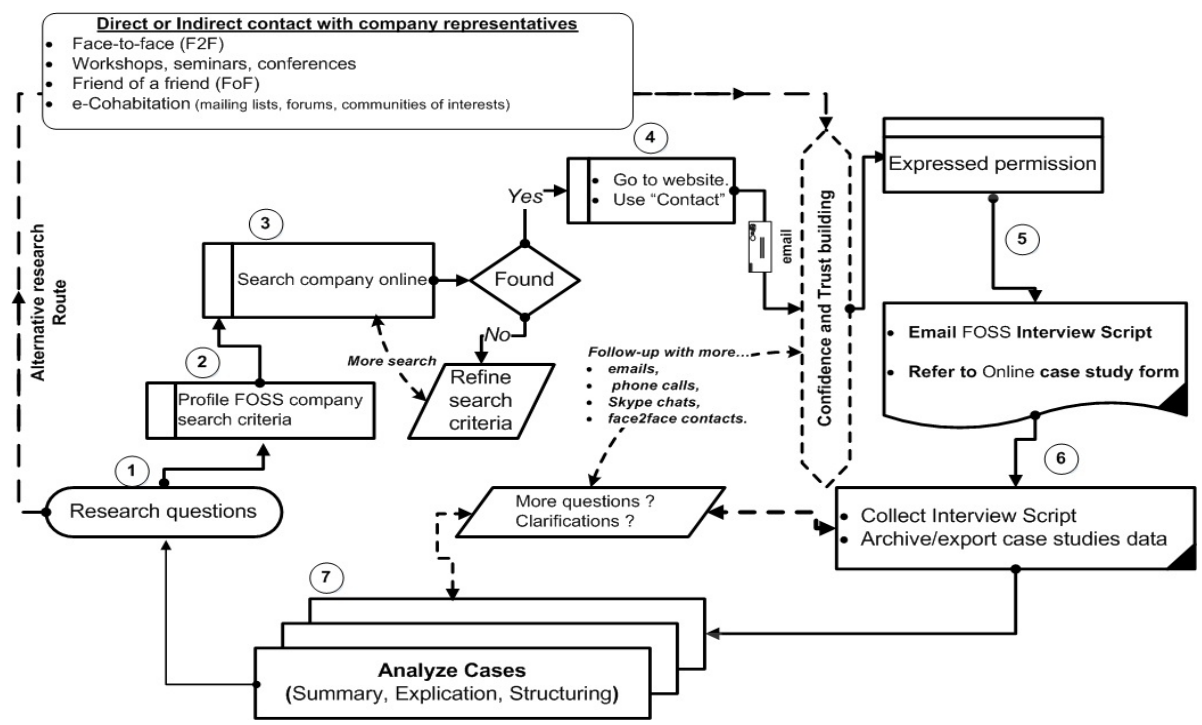

Fig. 1. Case Studies Methodology to Study FOSS Business Sustainability

In the first instance, an FOSS Interview Script, shown in box 1, was developed and used to collect the case studies data from the SMEs. The script consists of a set of case study research questions (Step 1), which are grouped into three main areas; Company profile, motivation for engaging in FOSS business, revenue generation or company's main source of income, and an experience report section. The script, which also has an online version, concludes with a case study feedback section where subjects as asked to indicate (Yes/No) whether they would like to receive further information about the case study they submitted and would like to be contacted for further clarification.

\begin{tabular}{|l|}
\hline Box 1: FOSS Interview Script for African ICT-based companies \\
Case Study Code: $\ldots$ \\
(e.g. SA01 meaning the $1^{\text {st }}$ case study from South Africa, country prefix SA) \\
Company profile: \\
Q1. Name/email of contact person: ...... \\
Q2. Country of residence: ...... \\
Q3. Name of the city/town where the company is located: ...... \\
Q4. Registered full name and acronym of the company: ...... \\
Q5. Company's web presence (if any) : ..... \\
Q6. When was the company established? $\ldots . .$. \\
Q7. How many people are employed in this company? ...... \\
Motivation for engaging in FOSS business: \\
Q1. Please describe your motivation for using Open Source in your business
\end{tabular}


Revenue generation or source of income:

Q1. Which services (e.g. ICT Training, Web Hosting, Software Development, Consultancy, etc.) are you offering? .......

Q2. If you are offering "FOSS/IT Outsourcing" as a service. Which of the following describes your outsourcing strategy? ......

a) Offshore outsourcing (e.g. to other countries outside Africa)

b) Onshore outsourcing (e.g. to other countries within Africa)

c) Both offshore and onshore outsourcing

Q3. Which service in Q1 is generating more income for your company? ......

Q4. What is your company's annual turnover (in USD)? ......

Q5. Who are your most prolific customers and the types of services they request most?

Q6. What are some of the strategies you use to market your products and services?

Q7. What are some of the difficulties, if any, you face in getting paid for the services you offer?

Q8. Please describe whether you are developing new products or customizing existing FOSS solutions (bespoke software) to fit your customers' needs?

Q9. Are you localizing (translating into local languages) some of your products?

\section{Experience Report:}

Q1. Looking at other companies (in and outside your country) who may be offering similar services as you do, what would you say works well for your company?

Q2. What is your advice for someone starting FOSS business in Africa in general and your country in particular? ......

Q3. Please describe three key problems you have encountered in running this kind of business and your solutions to those problems? ......

Q4. What are some of your business plans which will ensure the viability and sustainability of the business in the long run? ......

Case studies feedback:

Would you like to receive frequent updates about the status of the Case Study information you supplied (Yes/No)?

Subsequently, case study participants were given a choice to record their case study using either the Interview Script (emailed to them as attachment) or by completing the case study form online (Step 5). With the former choice, participants were asked if one week is sufficient to collect the FOSS interview script responses (Step 6). After five days, a reminder was sent asking if the interviewee is on course and will be able to submit responses. In some cases the responses collected generated more questions or more clarifications on some of the responses given was needed. Where this was the case, the interviewee was contacted again (using emails, phone calls, and Skype chats) and asked to provide more clarification before analyzing the case studies (Step 7).

Qualitative content analysis was used to describe each case study. Content analysis can be defined as "the study of recorded human communications" [3]. As a process, 
content analysis is the transformation of raw text data into a standardized, orderly form. In analyzing the case studies, three aspects of content analysis proposed by [18] were adopted:

- Summary: in summarizing the responses received from the case studies, attempts were made to preserve the essential content but still trying to capture the main ideas submitted by the interviewees.

- Explication: this process of re-examination and reading between the lines involves explaining, clarifying and annotating the responses supplied via the FOSS interview script or online case study form.

- Structuring: responses received from the companies follow the designed pattern of the FOSS Interview Script. The main aim of the structuring process is to filter out a structure from the responses provided and apply that structure in the analysis of the case studies. The outcome of the structuring process is what is used to profile each case study, as shown in table 3.

The methodology also shows an alternative research route. This "direct or indirect contact with company representatives" can act as a possible means of recruiting more case studies and bypassing the online search paths in Steps 2 - 4. This can take many forms; such as meeting company representatives face-to-face in workshops, seminars, conferences or through a friend of a friend, through participation in mailing lists, forums, social media where company representatives may be subscribed to; a phenomenon referred to in this research as "e-cohabitation".

\subsection{Case Studies Data}

Table 1 shows the major characteristics of the case studies, including the case study code, the geographical distribution of the companies studied, the year founded, and the staff strength of each company as of January 2012. As shown, the companies are relatively young and have been in existence, on the average, for 7.66 years. Furthermore, considering the European Commission's definition of SMEs [41], which considered a company to be an SME in terms of the number of employees and either turnover or balance sheet total, we can conclude that most or seven of the companies studied are micro- (ET01, KE01, NG01, SA02, SA03, TZ01, UG01). These SMEs have ten or less employees and are considered as the main forces in economic growth and job creation, not only in developed economies, but also in emerging economies or economies in transition [40]. MZ01 and SA01 can be described as small- since they have employees numbering more than ten and less than fifty employees. However, since this research was not able to register either the turnover or balance sheet totals of the companies, the term enterprise may be most appropriate to use to refer to the companies as entities engaged in an economic activity. They are, in effect characterized as "self-employed, family firms, partnerships and associations regularly engaged in an economic activity" [41]. 
Table 1. Major Characteristics of the Case Studies

\begin{tabular}{|l|l|l|c|c|}
\hline $\begin{array}{l}\text { Case } \\
\text { study } \\
\text { code }\end{array}$ & Country & Company Name & Year founded & No. of staff \\
\hline ET01 & Ethiopia & Amest Santim Systems & 2005 & 5 \\
\hline KE01 & Kenya & OpenWorld & 2004 & 7 \\
\hline MZ01 & Mozambique & SENFOSS & 2006 & 12 \\
\hline NG01 & Nigeria & Future Software Resources & 2008 & 5 \\
\hline SA01 & South Africa & GIS Global Image & 2000 & 17 \\
\hline SA02 & South Africa & Ntinga Information Systems & 2007 & 1 \\
\hline SA03 & South Africa & Linux Holding & 2003 & 1 \\
\hline TZ01 & Tanzania & Zalongwa Technologies & 2006 & 8 \\
\hline UG01 & Uganda & Linux Solution & 2000 & 10 \\
\hline
\end{tabular}

\section{$4 \quad$ Results and Discussions}

Table 2 shows the FOSS related business activities captured for each of the case studies. It is interesting to note that all the enterprises are engaged in developing and customizing FOSS solutions as part of their business activity. However, a conversation with the director of SA01 revealed that by FOSS development, most of the enterprises mean customizing the GUI and adding functionalities. Thus, it was not clear as to whether the enterprises are actually coding or developing FOSS solutions or just customizing existing FOSS. This might explain why in all the case studies, we have "Yes" for both software development and software customization. Nevertheless, this underscores one of the key, often understated attributes of FOSS, which is the considerable degree of flexibility and adaptability relative to proprietary software, which makes it possible to customize ICT solutions to fit business needs and operating processes of smaller organisations. All the enterprises are also involved in providing FOSS maintenance and support. With the exception of SA02, all the enterprises employ 'mixed' business activities involving both FOSS and proprietary software. For example, SA02 provides both FOSS and proprietary Geographical Information Systems (GIS) software solutions and services in the areas of system design and implementation, GIS consulting services such as Information Management Policies and GIS strategies. One explanation for this general trend is because, as noted in SA03 and KE01, clients request services on both FOSS and proprietary software. Most customers are just interested in whatever solution they can use to accomplish their objectives (UG01). This finding is in support of the AIM postulate [33] discussed earlier, which highlighted the increasing integration and co-existence in mainstream business computing ecosystems. There is also great consistency across the business cases relating to FOSS consultancy services, and the development and hosting of web services such as websites. Training is the only service that exhibited significant variation with half the respondents offering training services. 
Table 2. FOSS Business Activities Captured

\begin{tabular}{|c|c|c|c|c|c|c|c|c|}
\hline \multirow{2}{*}{$\begin{array}{l}\text { Case } \\
\text { study } \\
\text { code }\end{array}$} & \multirow[t]{2}{*}{ Company Name } & \multicolumn{7}{|c|}{ FOSS Business Activities Captured } \\
\hline & & Dev & Cus & Con & Tra & $\mathrm{MaS}$ & Web & $\begin{array}{l}\mathrm{Mi} \\
\mathrm{x}\end{array}$ \\
\hline ET01 & Amest Santim Systems & $\mathrm{Y}$ & $\mathrm{Y}$ & $\mathrm{Y}$ & $\mathrm{N}$ & $\mathrm{Y}$ & $\mathrm{Y}$ & $\mathrm{Y}$ \\
\hline KE01 & OpenWorld & $\mathrm{Y}$ & $\mathrm{Y}$ & $\mathrm{Y}$ & $\mathrm{Y}$ & $\mathrm{Y}$ & $\mathrm{Y}$ & $\mathrm{Y}$ \\
\hline MZ01 & SENFOSS & $\mathrm{Y}$ & $\mathrm{Y}$ & $\mathrm{Y}$ & $\mathrm{Y}$ & $\mathrm{Y}$ & $\mathrm{Y}$ & $\mathrm{Y}$ \\
\hline NG01 & Future Software Resources & $\mathrm{N}$ & $\mathrm{Y}$ & $\mathrm{Y}$ & $\mathrm{N}$ & $\mathrm{Y}$ & $\mathrm{Y}$ & $\mathrm{Y}$ \\
\hline SA01 & GIS Global Image & $\mathrm{Y}$ & $\mathrm{Y}$ & $\mathrm{Y}$ & $\mathrm{Y}$ & $\mathrm{Y}$ & $\mathrm{Y}$ & $\mathrm{Y}$ \\
\hline SA02 & Ntinga Information Systems & $\mathrm{Y}$ & $\mathrm{Y}$ & $\mathrm{Y}$ & $\mathrm{N}$ & $\mathrm{Y}$ & $\mathrm{Y}$ & $\mathrm{N}$ \\
\hline SA03 & Linux Holding & $\mathrm{Y}$ & $\mathrm{Y}$ & $\mathrm{Y}$ & $\mathrm{Y}$ & $\mathrm{Y}$ & $\mathrm{Y}$ & $\mathrm{Y}$ \\
\hline TZ01 & Zalongwa Technologies & $\mathrm{Y}$ & $\mathrm{Y}$ & $\mathrm{N}$ & $\mathrm{N}$ & $\mathrm{Y}$ & $\mathrm{Y}$ & $\mathrm{Y}$ \\
\hline UG01 & Linux Solution & $\mathrm{Y}$ & Y & $\mathrm{Y}$ & $\mathrm{Y}$ & $Y$ & $\mathrm{~N}$ & $\mathrm{Y}$ \\
\hline \multicolumn{9}{|c|}{$\begin{array}{l}\text { Dev. }=\text { Software development, } \text { Cus. }=\text { Customization, Con. }=\text { Consultancy, } \text { Tra. }=\text { Training, MaS }= \\
\text { Maintenance and Support, Web }=\text { Web base service development and hosting, Mix }=\text { both FOSS and } \\
\text { proprietary software, } \mathbf{Y}=\text { Yes, } \mathbf{N}=\text { No }\end{array}$} \\
\hline
\end{tabular}

Results of the qualitative content analysis of the case studies are summarized in table 3. In the summary each SME or enterprise is profiled according to FOSS business motivation, services offered and method of revenue generation, problems the company encounters in doing FOSS business and possible solutions, and lessons learnt about the unique way the company does business.

Some consistent themes and patterns of business practice were identified in the case responses. As distinct from the early years of the FOSS revolution, advocacy is a much less prevalent business motivation. Only one case [UG01] mentioned "encouraging FOSS adoption" as a motivation. Otherwise the range of business motivations were all anchored on the perceived value proposition of FOSS, including:

a) the use of FOSS as a low-cost tool in software/web development;

b) providing customizable FOSS business solutions; and

c) Using FOSS expertise as a service differentiator.

As reflected earlier in Table 2, there is a degree of consistency in the business models based on FOSS, with almost all of the cases offering a similar portfolio of services i.e. Consultancy, Software development \& Customization, Software Maintenance and Support, Web based service development and hosting, and generally supporting mixed computing environments with both FOSS and proprietary software. The business models resonate with the OSS2.0 archetypes suggested by [44] which suggested the emergence of small service centric software companies that thrive by providing training, technical support, and consultancy for local organizations that deploy open source products

Problems encountered, specific to FOSS, also fell generally into two categories;

a) managing and changing client perceptions of FOSS as a legitimate business computing solution; and

b) acquiring and maintaining the requisite level of resident FOSS expertise. 


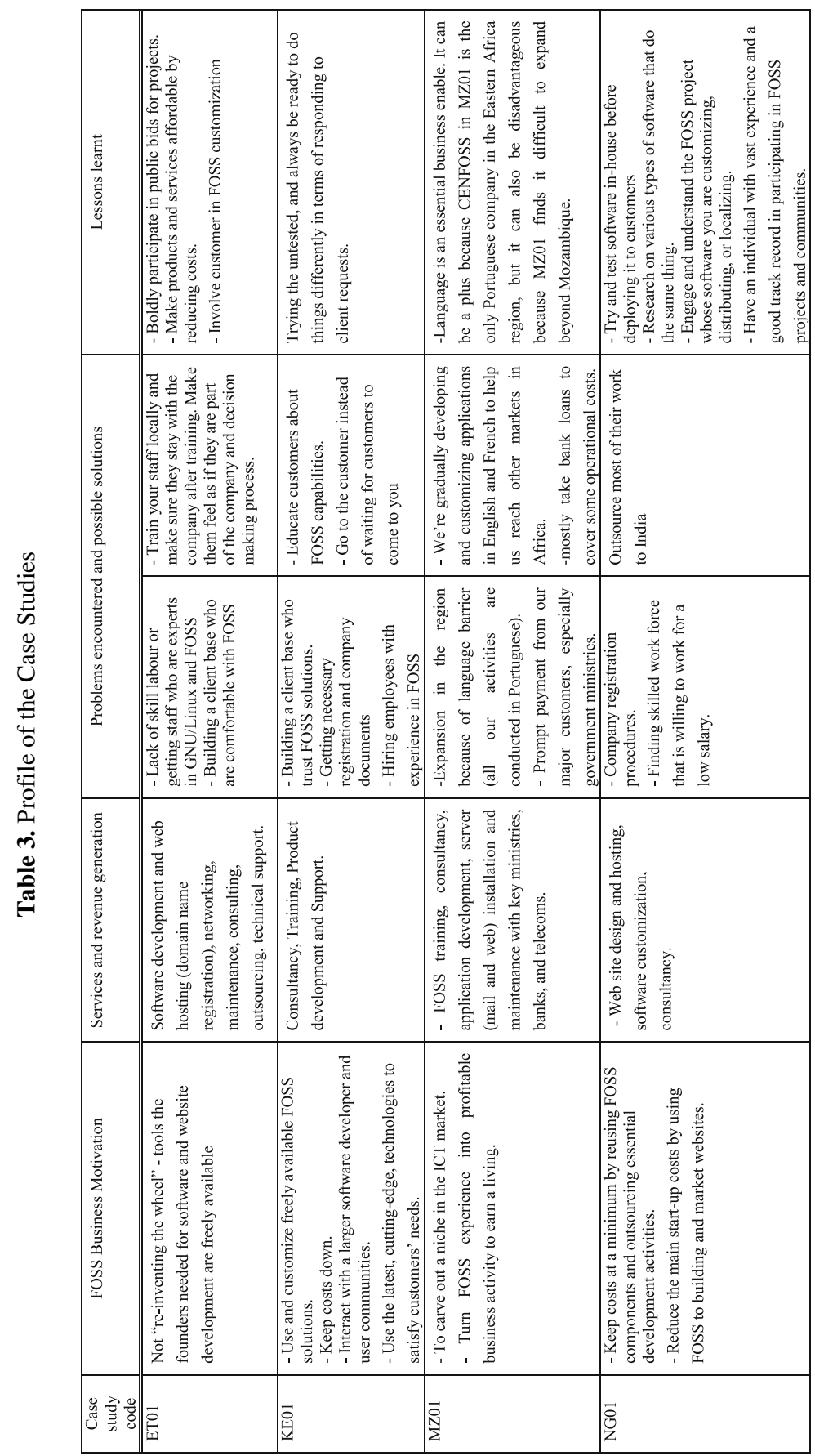




\begin{tabular}{|c|c|c|c|}
\hline & 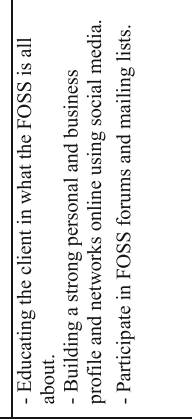 & 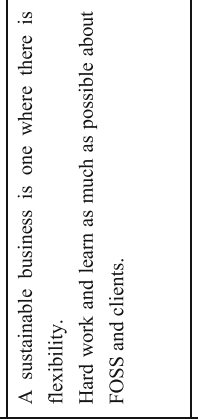 & 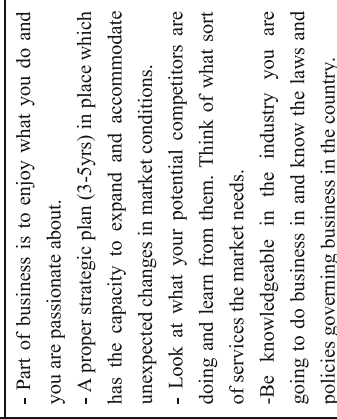 \\
\hline & 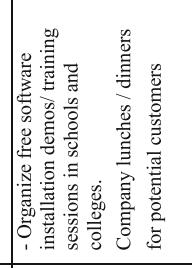 & 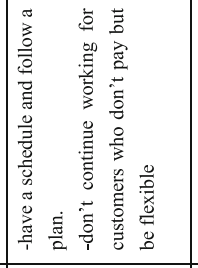 & 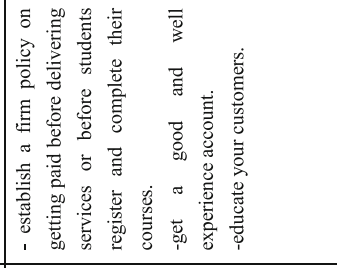 \\
\hline 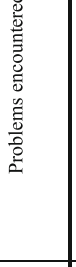 & 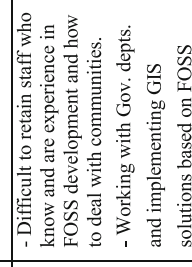 & 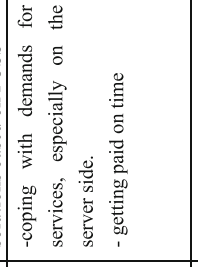 & 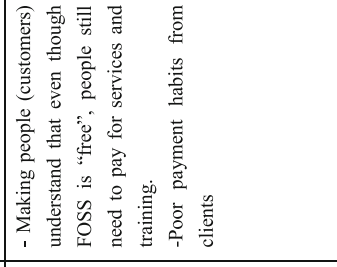 \\
\hline & 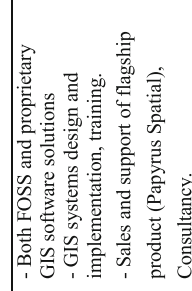 & 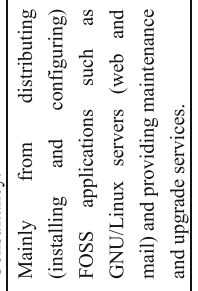 & 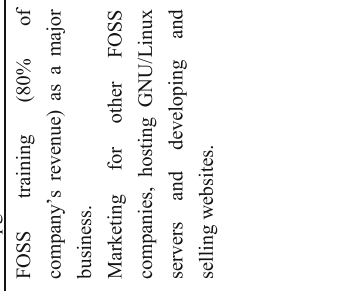 \\
\hline 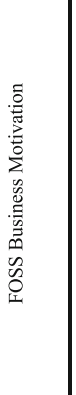 & 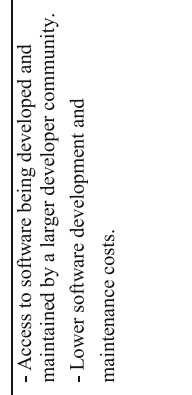 & 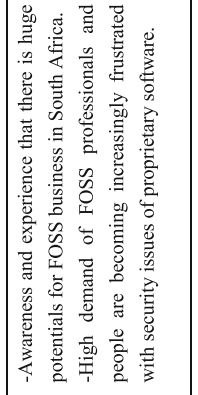 & 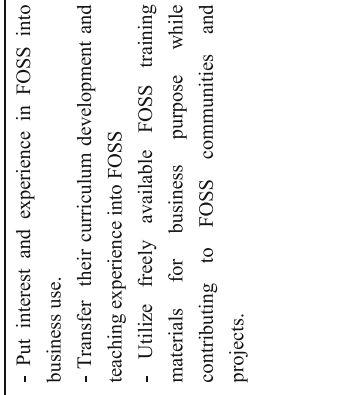 \\
\hline 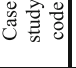 & 安 & $\frac{\tilde{c}}{\tilde{b}}$ & m \\
\hline
\end{tabular}




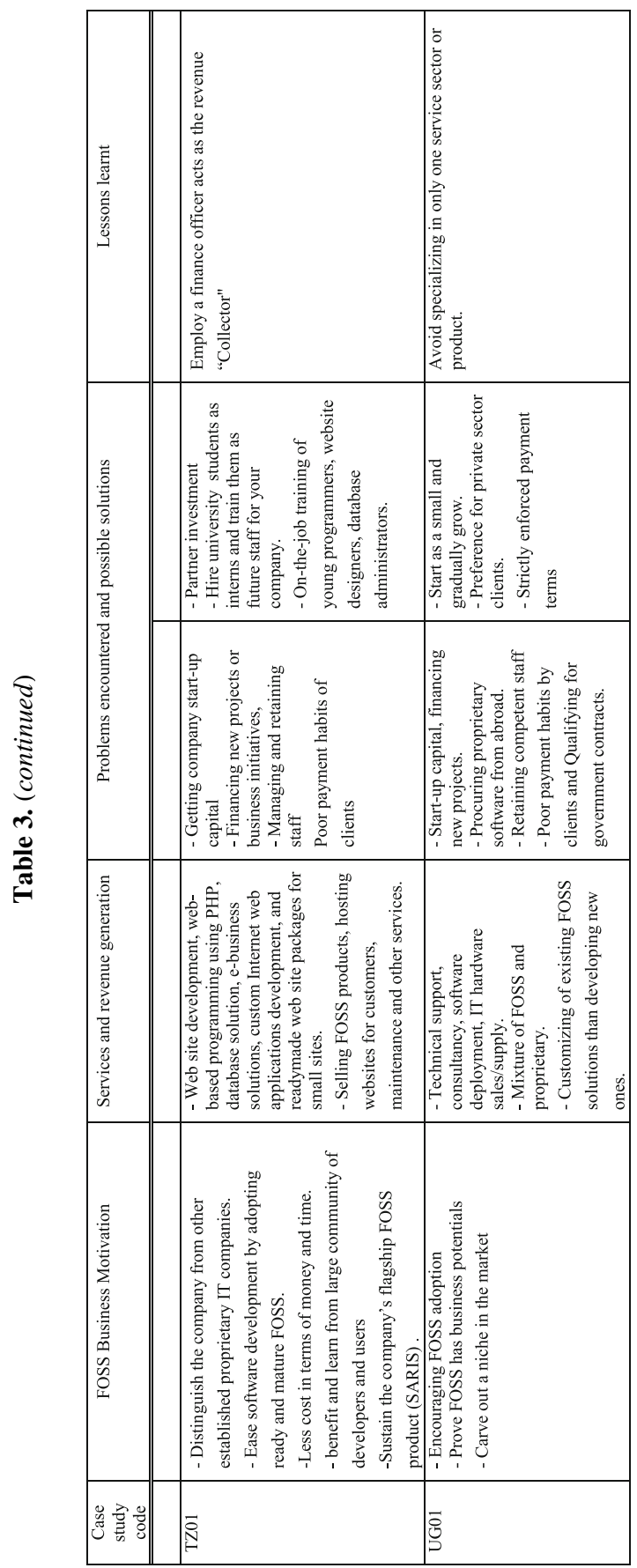


With increased FOSS adoption and use by SMEs within local, regional and national business ecosystems the latter challenge of maintaining the requisite level of resident, highly technical FOSS expertise is likely to manifest as a recurrent problem for service providers. This identifies a critical role for strategically placed community intermediaries as suggested by [45] that can provide aggregated technical services that are important to clusters of SMEs to facilitate the adoption of complex ICT applications. These challenges also suggest opportunities for Policy interventions at the state or national level that will endorse and encourage the legitimacy and use of FOSS, as a means of stimulating the indigenous software industry, creating local jobs and entrepreneurial opportunities.

\subsection{Validity Threats}

While this research may have provided some insight into the business potential for ICT-based enterprises in Sub-Saharan Africa, we have only introduced nine case studies from seven out of possible fifty-four African countries. Given the increasing prominence of FOSS on the continent, we posit that there are many more enterprises leveraging FOSS for business purpose. There might even be variations in FOSS business practices by enterprises within the same country or region. Furthermore, since our case studies are just from English speaking Africa, language may even be a factor that can bias our sample. Thus, there is danger in generalizing the results presented here to the entire African FOSS business ecosystem. However, as [42] found out in their study of the Apache web server, the analysis of sometimes few cases or even a single case can provide important insights and ground for future research in this area. Therefore, we hope that the methodology and analytical framework provided in this paper can form the groundwork for further research work to investigate FOSS business sustainability and innovation in Sub-Saharan Africa.

\subsection{Future Work}

The research presented in this paper has opened avenues for future work which may provide supplementary information to help researchers further understand FOSS business sustainability and innovation in Sub-Saharan Africa. As a follow-up to this research an online "FOSS Case Studies for African ICT Companies"" is being launched to provide more case studies for this kind of research. More case studies data will help ICT4D, entrepreneurs, and Information Systems researchers better understand the trend in FOSS business innovation activities over time and the factors influencing them.

\section{Conclusion}

This research presented and discussed how small businesses in Sub-Saharan Africa are leveraging the benefits inherent in FOSS to create sustainable businesses. The

\footnotetext{
${ }^{1}$ http: / / servnet.ias . unu . edu/limesurvey/index . php? sid=67749\& lang=en, Last accessed, May 15, 2012.
} 
literature review highlighted the global trend, economic impact, and sustainability aspects of FOSS and how all these factors come into play to provide unique technology opportunities for Sub-Saharan Africa. A methodology was presented to show that a case study research approach can be a possible means of investigating how ICT businesses are using and benefiting from FOSS. In the analysis, each case study was presented showing the profile, FOSS business motivation, and the services offered. Problems encountered and solutions adopted in operating a mix FOSSproprietary software business in the particular country, as well as lessons to be learnt from the way the companies do business was also presented.

The case studies showed that FOSS provides an alternative business model option for ICT firms in Sub-Saharan Africa. However, operating solely on FOSS solutions and services is not a sustainable business option. Rather, companies operate a form of quasi-business; taking advantage of the low cost and ability opportunities to customize FOSS solutions, and at the same time selling and doing maintenance of proprietary software. Furthermore, the companies' main motivation for engaging in FOSS business is driven by reduction in the cost of software development and deployment. For most of the companies, the software they needed to start a business (e.g. building websites, deploying and maintain a learning management system) was readily available as FOSS. This helped them avoid problems, such as purchasing and paying high licenses cost, associated with associated with starting a business with proprietary software.

The qualitative nature of the study, provides insights into the emerging FOSS business models in sub-Saharan Africa, problems encountered by businesses and lessons to be learnt from the case studies individually and collectively. It provides a basis for replication in other developing contexts, as well more extensive quantitative studies, based on the trends and factors highlighted. In conclusion, similar to the advice given to China's software industry by [21], this research ascertains that there is substantial evidence from these case studies to suggest that Africa should focus on its domestic software market as a starting point and develop a more comprehensive strategy for the long term. The study highlights opportunities for Policy interventions that can help to stimulate the growth and development of entrepreneurs and existing businesses that base their business model on FOSS. Such interventions could seek to endorse the legitimacy of FOSS, and demonstrate by example through Government's own adoption and use of FOSS. Such initiatives could help to deflect the level of uncertainty or distrust that may continue to persist among prospective FOSS business clients and could also help to stimulate greater investment in FOSS training and expertise in the sector, two of the challenges cited by respondents in the case study.

Acknowledgment. The first author wishes acknowledge the Japan Society for the Promotion of Science (JSPS) for funding this research under the Grant-in-Aid number: P10807. The authors wish to extend sincere gratitude and thanks to the companies for providing the case studies data. We are greatly indebted to the three anonymous reviewers for their constructive comments and suggestions which helped us improve the quality of the original manuscript submission. 


\section{References}

[1] Actuate. Open Source Enters the Mainstream. The Acutate Annual Open Source Survey (2008), http: / / www . actuate. com/company/news / pressrelease/ ?articleid=13847 (accessed, Monday, August 16, 2010)

[2] Actuate. The 2009 Actuate Annual Open Source Survey (2009), http: / /www . actuate. com (accessed, Thursday, August 19, 2010)

[3] Babbie, E.: The practice of social research, 9th edn. Belmont, Wadsworth (2001)

[4] Pamela, B., Susan, J.: Qualitative Case Study Methodology: Study Design and Implementation for Novice researchers. The Qualitative Report 13(4), 544-559 (2008)

[5] Pfaff, B., David, K.: Society and open source. Why open source software is better for society than proprietary closed source software (1998), http://benpfaff.org/ writings / anp/oss-is-better.html (accessed, Thursday, August 19, 2010)

[6] Peter, C., Steven, F., Steve, G., David, S.: A history of IBM's open-source involvement and strategy. IBM Systems Journal 44(2), 249-257 (2005)

[7] CATIA. Catalysing Access to ICTs in Africa (CATIA) programme, Free/open source software (FOSS) policy in Africa: A toolkit for policy-makers and practitioners, bridges. org and the Collaboration on International ICT Policy for East and Southern Africa (CIPESA) (2005)

[8] Carlo, D.: FLOSS Guide for SMEs (2009), http: / /guide.flossmetrics .org/ index.php/3._Basic_FLOSS_adoption_models (accessed, Thursday, August 19, 2010)

[9] Dice and The Linux Foundation. 2012 Linux Jobs Report (February 16, 2012)

[10] FOSSDeva. FOSS for Sustainable Development in Africa (FOSSDeva) Survey (2011), http : / / servnet. ias . unu . edu / limesurvey / index . php? sid=86668\&l ang=en (valid until August 31, 2012)

[11] Michael, F.: Worldwide Open Software Forecast. International Data Corporation (IDC), document Nr. 219260 (2009)

[12] Gartner Inc., User Survey Analysis: Open-Source Software, Worldwide (2008), http: / / www.gartner.com/DisplayDocument?ref=g_search\&id=7579 $16 \&$ subref $=$ simplesearch (accessed March 10, 2009)

[13] Ghosh, R.: Economic Impact of FLOSS on Innovation and Competitiveness of the EU ICT Sector (2006), http: / / ec.europa.eu/enterprise/sectors/ict/ files/2006-11-20-flossimpact_en.pdf (accessed, Tuesday, August 17, 2010)

[14] Goode, S.: Something for nothing: management rejection of open source software in Australia's top firms. Information and Management 42(5), 669-681 (2005)

[15] Gross, M.: Productive Anarchy? Networks of Open Source Software Development, Forum: Qualitative Social Research 8(1) (2007), http://www. qualitativeresearch.net/index.php/fqs/article/view/225 (retrieved September 4, 2010)

[16] Gurbani, V.K., Garvert, A., Herbsleb, J.D.: A case study of a corporate open source development model. In: Proceedings of the 28th International Conference on Software Engineering, Shanghai, China, pp. 472-481 (2006)

[17] i2010, Preparing Europe's digital future. i2020 Mid-Term Review, A European Information Society for growth and employment. COM (2008) 199, SEC (2008) 470, vol. (1-3), http: / / ec . europe.eu/i2 010 (accessed, Thursday, August 19, 2010)

[18] Kohlbacher, F.: The Use of Qualitative Content Analysis in Case Study Research. Forum: Qualitative Social Research 7(1), 1-23 (2006) 
[19] Morgan, L., Finnegan, P.: Open Innovation in Secondary Software Firms: An Exploration of Managers' Perceptions of Open Source Software. The Database for Advances in Information Systems 41(1), 76-95 (2010)

[20] Dwomoh-Tweneboah, M.: Information Technology for Africa. In: iBiz2008 Workshop for Net Business Ethics, Honolulu, USA, February 10-11 (2008)

[21] Li, M., Lin, Z., Xia, M.: Leveraging the Open Source Software Movement for Development of China's Software Industry. Information Technologies and International Development 2(2), 45-63 (2004)

[22] Morgan, L., Finnegan, P.: Open innovation in secondary software firms: an exploration of managers' perceptions of open source software. SIGMIS Database 41(1), 76-95 (2010)

[23] Jabu, M., Elmarie, B.: An investigation into the implementation of open source software within the SA government: an emerging expansion model. In: SAICSIT 2008: Proceedings of the 2008 Annual Research Conference of the South African Institute of Computer Scientists and Information Technologists on IT Research in Developing Countries, pp, pp. 148-158 (2008)

[24] Munga, N., Fogwill, T., Williams, Q.: The Adoption of Open Source Software in Business Models: A Red Hat and IBM Case study. In: SAICSIT 2009, pp. 112-121 (2009)

[25] OSOR (n.d) The Open Source Observatory and Repository for European public administrations, https://joinup.ec.europa.eu/page/osor.eu (accessed, Thursday, March 1, 2012)

[26] Raymond, E.S.: The Cathedral and the Bazaar. In: Musings on Linux and Open Source by an Accidental Revolutionary, O'Reilly \& Associates, Inc., USA (2001)

[27] van Reijswoud, V., de Jager, A.: Free and Open Source Software for Development: exploring expectations, achievements and future. Polimentrica Published Book, Italy (2008)

[28] Watson, R.T., et al.: The Business of Open Source: Tracking the changing competitive conditions of the software industry. Communication of the ACM 51(4), 41-46 (2008)

[29] Ajila, S., Wu, D.: Empirical study of the effects of open source adoption on software development economics. Journal of Systems and Software 80(9), 1517-1529 (2007)

[30] Samuelson, P.: IBM's pragmatic embrace of open source. Commun. ACM. 49(10), 2125 (2006)

[31] Sowe, S.K., Stamelos, I., Samoladas, I. (eds.): Emerging Free and Open Source Software Practices. IDEA Group Publishing, Hershey (2008)

[32] Sowe, S.K., Ioannis, S., Angelis, L.: Understanding Knowledge Sharing Activities in Free/Open Source Software Projects: An Empirical Study. Journal of Systems and Software 81(3), 431-446 (2008)

[33] Sowe, S.K.: Free and Open Source Software in Business: Implications for Policy Efficiency. In: International Conference of the Open Source Software Business Information Group (OSSBIG 2011), Vienna, Austria, May 31 (2011b)

[34] Stamelos, I., Angelis, L., Oikonomou, A., Bleris, G.L.: Code quality analysis in open source software development. Information Systems Journal 12, 43-60 (2002)

[35] UNCTAD. Free and Open-Source: Implications for ICT Policy and Development. Chapter 4, E-Commerce and Development Report. UNCTAD/SIDTE/ECB/2003/1 (2003)

[36] Stephen, W., Gynn, D., von Rotz, B.: The Growth of Open Source Software in Organizations. Publication Report. Optaros Inc. (2005)

[37] Yin, R.K.: Case Study Research, 3rd edn. Sage, Thousand Oaks (2003) 
[38] Chapter 7: Open Source Software Adoption Best Practices: Myths, Realities, Processes and Economic Growth

[39] Imed, H.: Open Source Ecosystem in Tunisia: An Empirical Study. In: Sowe, S.K., Parayial, G., Sunami, A. (eds.) Free and Open Source Software and Technology for Sustainable Development, ch. 9, pp. 153-170. UNU-Press (2012)

[40] Maurice, M., Sherly, T., Evan, D.: Adoption and Diffusion patterns of FOSS in Jamaican SMEs: A Study of Perceptions, Attitudes and Barriers. In: Sowe, S.K., Parayial, G., Sunami, A. (eds.) Free and Open Source Software and Technology for Sustainable Development, ch. 10, pp. 171-185. UNU-Press (2012)

[41] European Commission (2003/361/EC). THE New SME Definition. User Guide and Model Declaration. Official Journal of the European Union L 124, 36 (May 20, 2003)

[42] Mockus, A., Fielding, R., Herbsleb, J.A.: Two case studies of open source software development: Apache and Mozilla. ACM Transactions on Software Engineering and Methodology 11(3), 1-38 (2002)

[43] Brown, D., Lockett, N.: Potential of critical e-applications for engaging SMEs in ebusiness: A provider perspective. Journal of Information Systems 13(1), 21-34 (2004)

[44] Fitzgerald, B.: The Transformation of Open Source. Software. MIS Quarterly 30(3), 587-598 (2006)

[45] Brown, D., Lockett, N.: Potential of critical e-applications for engaging SMEs in ebusiness: a provider perspective. Journal of Information Systems 13(1), 21-34 (2004) 